\title{
African Climate Refugees: Environmental Injustice and Recognition
}

\author{
Suzi Mohammed Rashad \\ Political Science Department, October 6 University, Cairo, Egypt \\ Email: suzirashadnet@yahoo.com
}

How to cite this paper: Rashad, S. M. (2020). African Climate Refugees: Environmental Injustice and Recognition. Open Journal of Political Science, 10, 546-567. https://doi.org/10.4236/ojps.2020.103033

Received: June 3, 2020

Accepted: July 24, 2020

Published: July 27, 2020

Copyright $\odot 2020$ by author(s) and Scientific Research Publishing Inc. This work is licensed under the Creative Commons Attribution International License (CC BY 4.0).

http://creativecommons.org/licenses/by/4.0/ (c) (i) Open Access

\begin{abstract}
The aim of the study is to discuss the effects of climate change in the African continent, which has suffered the repercussions of environmental and climate deterioration, most notably "environmental displacement" or what is called "climate refugees." The findings demonstrate that although the phenomenon of "climate refugee" has become noticeable in the African continent, and despite concrete efforts by Africa, the lack of international recognition of the term "climate refugee" as well as the lack of environmental justice in distributing the burdens of global warming, remains an obstacle for the African continent for solving this problem. Therefore, international synergy is required to find common solutions. So the importance of the study lies in highlighting the insufficiency of African efforts to reduce the phenomenon of environmental refugees, and the lack of international efforts to establish a legal framework for this problem.
\end{abstract}

\section{Keywords}

Africa, Climate Refugee, Climate Change, Environmental Justice

\section{Introduction}

The concept of "environmentally displaced people in Africa" is a worrying phenomenon whereby many people have been forced to leave their homes due to environmental changes that threaten their lives and livelihood. To date, millions of people have been displaced due to problems associated with environmental destruction and climate change. The UN Secretary-General, António Gutiérrez, and head of the UN High Commissioner for Refugees, Filippo Grandi, noted this phenomenon at the opening of the Global Refugee Forum 2019 in Geneva, when discussing how climate change is creating refugees and fueling conflict, particularly in the Sahel region of Africa. 
Researchers have long avoided discussing displacement due to climate problems and have ignored the phenomenon of environmental refugees. However, theoretical interest in the role of environment in international relations has been emerging, and with the emergence of "Green International Relations Theory," the concepts of environmental justice, environmental security, and the role of non-human environmental factors in international interactions have gained traction, with many voices now calling for discussion of environmental issues. Hence, in response to climate change, which has been affecting countries worldwide, particularly the African continent, environmental experts have framed several viewpoints on the interrelationship between climate change and asylum, or so-called climate, environmental, or ecological asylum.

Therefore, the importance of this study lies in the fact that it illustrates the insufficiency of the African efforts exerted to face the issue of climate refugees, in light of the existing lack of environmental justice among the countries of the North and those of the South, as well as the lack of international codification of the concept of "climate refugee".

The main objective of this paper is threefold:

1) Clarifying the problematic concept of "Climate Refugee";

2) Determining the negative effects on the African continent that are resulting from environmental degradation; which had been a result of climate change; and

3) Evaluating the African efforts to combat the phenomenon.

Hence, this paper aims to answer the following questions:

Q1. What is the concept of "Climate Refugee" and how is it situated regarding international recognition?

Q2. How large has the environmental degradation been in Africa; and what has been its impact on increasing the phenomenon of climate refugees?

Q3. How sufficient are the African efforts to combat the environmental degradation and the resulting waves of displacement?

This research argues that in light of environmental injustice, the lack of official international recognition of "environmental refugees" remains a hindrance to the efforts of the African continent in the field of environment and policies for internally displaced people in general. Therefore, this study attempts to clarify these issues by studying three main sections. Section one presents the theoretical and conceptual framework for the "climate refugee". Section two discusses the aspects of environmental degradation in the Horn of Africa. Section three highlights the African efforts to combat that phenomenon and the conclusions and recommendations for enhancing African efforts are presented in Section four.

\section{Literature Review}

1) Studies of the concept of climate refugee: These studies dealt with various causes of displacement; mainly the reasons for the deterioration of environmental factors and conditions of life, such as the degradation of arable land, and the 
lack of rain that was associated with an increase in the population, which created the so-called "Population Pressure" on the resources and induced a difficulty in providing a solution to it (Myers, 1993). Lonergan (1998) also referred to the so-called "Environmental Persecution" as a factor for displacement that causes environmental destruction created by the development projects carried out by the authorities or investors, while in return, not working to protect the victims and those affected.

Other studies also tackled the legal aspects of the "Climate Refugee". Hugo, (1996) argued that the concept of "Climate Refugee" has no legally-pound concept that would enable distinguishing it from the concept of the "immigrant" or the "immigrant for environmental reasons", and also stating that the matter must be handled in accordance with the standards of the "control over the decision to leave or to stay".

2) Studies of the environmental displacement in Africa, including an article by Oliver Ruppel and Santana van Wyk (2013) that reviews the potential and expected impacts of climate change on some components of human security in Africawhich is one of the continents that are most vulnerable to climate change and volatility to climate fluctuations. In it, such fluctuations would not only have the capacity to impose additional pressures on human security and exceeding and surpassing the adaptive capabilities of societies but also affect a variety of issues of conflicts, violence, and terrorism, especially during droughts as was the case in Somalia, Kenya, and Eritrea (Terdiman, 2013).

\section{The Concept of "Environmental Refugee" from the Green Perspective in International Relations}

The field of international relations is concerned with environmental issues and is creating new discourse in international relations theory, including concepts such as "ecological security" and "environmental justice." There has also been an emerging interest in the role of non-human environmental elements and their impact on "non-human nature," all of which were a prelude to "green theory" in international relations. Green theory argues that some countries and social groups are unjustly utilizing more than their fair share of environmental resources at the expense of other groups that have no knowledge of environmental decisions that may affect them. Therefore, the goal of the theory is twofold: 1) To reduce the environmental risks in all areas, and 2) To prevent environmental risks from being unfairly transferred to other parties (Wackernagel \& Rees, 1998).

Green theory or "Green International Relations Theory" seeks to transcend the country-centered frameworks of traditional international relations theory and provide new normative and analytical visions of global environmental changes. It is divided into two parts: The first part is concerned with analyzing global environmental problems, while the second is concerned with new normative concepts, such as environmental justice and green democracy at all levels of government. According to this theory, to achieve "environmental justice" the 
following must be taken into account:

1) All those affected by environmental hazards from existing peoples, future generations, and non-human creatures must be acknowledged.

2) Those at risk must participate in the environmental decision-making process, including decision-making, supervision, enforcement, and control.

3) A precautionary approach should be adopted that minimizes risks for society as a whole.

4) Risks should be equitably distributed, including integrating all perspectives of all affected parties and groups calling for the public interest.

5) Groups that are suffering from the effects of environmental problems should be compensated.

In Paterson's (2000) book Understanding Global Environmental Policies: Control, Cumulative, Resistance, he emphasizes that green international relations theory should begin with three fundamental questions: Why did environmental problems arise or how are they produced? What are the effects of environmental problems on different social groups? What is the due response? Paterson believes that environmental problems result from overlapping structural relations between states and major institutions and the administrative concepts governing those institutions, and that there is an uneven distribution of environmental risks. He also clarifies the spatial and temporal dimensions between those who benefit from the social practices that produce those risks, and those who ultimately suffer from them. Regarding due response to risks, Paterson (2000) sees the value of resisting the interconnected structures, and building steady state-related economies based on equal social principles.

Green Theory contributes to the study of climate change through its analysis of international political problems regarding climate change; its role was apparent in the emergence of new normative discourses that generated alternative political proposals to those prevailing on the international scene.

\section{Environmental (Climate) Refugees}

Green theorists consider the injustices generated by climate change to be manifestations of environmental injustice in general. Poor societies (particularly in the south) produce a relatively low percentage of carbon emissions per capita compared to the rich consuming classes in the north. However, these poor societies will likely be the most affected by global warming, the least able to adapt to climate-related damage, and the least protected against it. Therefore, action must be taken to avoid the risks resulting from the uneven distribution of risks associated with climate change. Comprehensive environmental laws must be formulated based on equal rights for everyone. In relation to "Environmental Security," proponents of green theory are divided regarding how to handle it. Some researchers query whether environmental problems should be placed in the context of security problems with the aim of raising them to "high policy" status. They believe that this may be counterproductive, and simply playing on traditional security issues, rendering them void of content and deviated from the 
fundamental green values that are against violence (Deudney, 1990). However, other researchers find within "Environmental Security" the potential to broaden both the ethical scope of security and the traditional understanding of the source of insecurity, thus potentially enhancing international cooperation for the sake of long-term sustainability (Eckersley, 2007).

Numerous studies have focused on environmental matters, climate change issues, environmental conflicts, and ecological security. Among the authors who have linked environmental problems to population growth was Norman Myers (1993), who estimates that environmental refugees will soon become the largest group of involuntary immigrants worldwide. Myers is concerned with so-called "population pressure" as a decisive factor in environmental degradation and reflects that environmental refugees are actually "population pressure" refugees (Myers, 1993). He also claims that by 2050, the number of climate refugees will reach 200 million and he identified four main causes of displacement (see Table 1).

1) The first is gradual environmental changes, including land degradation and climate change, which Myers attributes to a lack of arable land, poor agricultural practices, and lack of rural infrastructure for agriculture, population growth, and poverty. These factors impact the livelihoods of many residents. With climate change and an increase in greenhouse gas emissions by rich countries, environmental refugees are considered incapable victims resident outside the exporting countries, who are not responsible for the change process.

2) The second cause of population displacement is natural disasters. Environmental refugees are victims of disasters, poverty, and demographic pressures, but due to their impoverished condition, they can do little to protect themselves.

3 and 4) The two other causes are "environmental accidents" and "crises," which result from infrastructure projects where affected people are victims of resettlement within their own countries. This cause is attributable to the direct

Table 1. Distinguishing migration currents caused by environmental disturbances into three categories of disturbances that include: disasters, confiscation of property, and deterioration.

\begin{tabular}{|c|c|c|c|c|c|c|}
\hline \multirow[b]{3}{*}{ Sub-Category } & \multicolumn{2}{|c|}{ Disaster } & \multicolumn{2}{|c|}{ Exportation } & \multicolumn{2}{|c|}{ Deterioration } \\
\hline & \multicolumn{2}{|c|}{$\begin{array}{l}\text { An unintended, catastrophic } \\
\text { event triggers human migration }\end{array}$} & \multicolumn{2}{|c|}{$\begin{array}{l}\text { The willful destruction of the } \\
\text { environment renders it unfit } \\
\text { for human habitation }\end{array}$} & \multicolumn{2}{|c|}{$\begin{array}{l}\text { An incremental deterioration of } \\
\text { the environment compels } \\
\text { migration as constraints to } \\
\text { human survival increase }\end{array}$} \\
\hline & Natural & Technological & Development & Ecocide & Pollution & Depletion \\
\hline Origin & Natural & Anthropogenic & Anthropogenic & Anthropogenic & Anthropogenic & Anthropogenic \\
\hline Intention of Migration & Unintentional & Unintentional & Intentional & Intentional & Unintentional & Unintentional \\
\hline Duration & Acute & Acute & Acute & Acute & Gradual & Gradual \\
\hline General Example & Volcano & Meltdown & Dam Building & Defoliation & Global Warming & Deforestation \\
\hline Estimated Number Displaced & 7000 & 144,000 & 1.3 million & 7 Million* & 15 million & 115,000 \\
\hline
\end{tabular}

Source: Bates (1996). ${ }^{\star}$ Reflects all types of refugees as a result of warfare 1967-1973. Sources: Montserrat: Monastersky 1997:101; US-TMI: Miller 1991: 423; China: Lou 2000: 23; Vietnam: Glassman 1992:28; Bangladesh: Myers 1993a: 754: Ecuador: Bates 2000: 25. 
or indirect involvement of the governments of these countries in bringing about such environmental changes due to the infrastructure projects they are establishing. According to Lonergan (1998: pp. 5-15), such refugees are to be called "refugees of environmental persecution," with "environmental persecution" comprising "the environmental destruction caused by the development projects in the region, which is carried out by the authorities that are not protecting the victims; who are supposed to be protected".

Sociologists studying environmental refugees have provided many valuable reviews of the current literature, including Ramlogan (1996), Perout (1995), Sukeke (1994), and Westing (1992). These reviews have preserved the concept of the "environmental refugee" developed by the United Nations Environment Program (UNEP) in 1985. UNEP identified environmental refugees in a manner consistent with the agency's humanitarian mission rather than using more analytical criteria. UNEP researcher Issam El-Hinnawi (1985) first defined environmental refugees as "those people who have been forced to leave their traditional habitats, temporarily or permanently, due to a marked environmental disorder (natural and/or human-induced) as it endangers their existence and/or affects them in a way that is dangerous to the quality of their lives." In this definition, the "environmental disorder" means any physical, chemical, and/or biological changes in an ecosystem (or resource base) that make it, temporarily or permanently, unsuitable for human life.

In his 1985 report, El-Hinnawi described three main types of environmental refugee based on a time-wise criterion:

1) Those temporarily displaced by disasters, whether natural or anthropogenic, which are described as "environmental stress," such as floods, hurricanes, and earthquakes;

2) Those permanently displaced due to severe environmental changes, such as a dam construction;

3) Those that migrate on the basis of the gradual deterioration of environmental conditions, such as deforestation and desertification, so that the surrounding environment is no longer able to meet their humanitarian needs. This is an additional but smaller category.

El-Hinnawi gave an approximate description, but did not set general criteria for distinguishing one type of environmental refugee from another. The literature that developed after this report preserved El-Hinnawi's vague system of classification.

Criticisms of the current literature on environmental refugees have been summarized in three main points (Bates, 2002). Firstly, studies on environmental refugees show a strong regional bias, focused in specific areas such as Africa and Asia and therefore lacking focus on other regions. Secondly, detailed case studies of the conditions that produce environmental refugees are rare. Thirdly, scholars of international law, security concerns, and broader issues related to migration resist using the term "refugee." All of these weaknesses arise, at least in part, from the non-critical acceptance of the mysterious concept of environ- 
mental refugees presented by El-Hinnawi.

The concept of "environmental migration" has no legal definition; therefore, it is seen as a link in the chain of departure or transition, the rings of which begin in the form of a straight line with three rings distributed from far right to far left (Hugo, 1996). Its first link starts from the far right in parties who have control over the decision to force people to move, who are called "migrants." The second episode in the middle comprises parties who control to a lesser degree the decision to move due to limited options; these are called "environmental emigrants." The last link, which represents the far left, comprises parties who have no control over the decision to leave, i.e., this decision is involuntary; these are called "environmental refugees."

However To clarify the concept, the current environmental refugees thought distinguishes these groups based on the origin (natural or technological) and duration (acute or progressive) of the environmental disorder, and whether migration is the result of a planned interruption (intentional or not) (see Table 1).

Although the agreed-upon definition of environmental refugees is "people who migrate from their usual place of residence because of changes in their surrounding non-human environment," (Renaud, Dun, Warner, \& Bogardi, 2011) this definition remains vague in two respects: first, in confirming that the surrounding environment has become less suitable for human existence; and second, in recognizing that these conditions cause migration.

\section{Environmental Refugees under International Law}

The 1951 UN Refugee Convention and its 1967 amendment define refugees as people "who have a strong fear of persecution for reasons of race, religion, nationality, membership of a particular social group, or political opinion." Under the Convention, migrants who meet these criteria are called "refugees," while others are considered "voluntary migrants." In the case of environmental migration, migrants who have been forced to move due to uncontrolled conditions and where their options are restricted, are to be labeled as "environmental refugees." Due to its significant restrictions, the Geneva Convention does not protect victims of environmental disasters. These restrictions are related both to the protection it provides and its relevance to the new types of international migration. Furthermore, in the Convention, the concept of "persecution" is closely related to fear of personal persecution, thus neglecting the underlying public persecution in situations of disaster and pressing environmental situations.

Under the Geneva Convention, "persecution" means unjust treatment, and this does not cover victims of tsunami, drought desertification, etc. Moreover, an asylum seeker must demonstrate that he/she has left his/her country and that that country is not providing him/her with adequate protection. In most cases, however, environmental migration is internal and occurs under the protection of the state, even if that state had insufficient capability or is even powerless in the face of sudden environmental disasters. This means that those who are displaced within their own countries of origin due to a catastrophe do not fall within the 
scope of the Geneva Convention, even if the affected country is unable to provide them with effective protection. This is because the Geneva Convention is based on the principle of "respect for international law and national sovereignty," and because the principle of "non-interference in the affairs of States and respect for territorial integrity" prevents the protection of internal refugees (Ruppel \& van Wyk, 2013).

Accordingly, there is a difference between "traditional refugees" and "environmental refugees." While traditional refugees no longer enjoy the legal protection of their country of origin or country of nationality, environmental refugees have not broken their legal relationship with their country, nor has this relationship been broken, but it is temporarily not subject to functioning and implementation. Furthermore, while a "traditional refugee" must overcome the legal disconnection between him/her and his/her country of origin, an "environmental refugee" must alleviate the material deficiencies of his/her country without necessarily having to change that legal bond. Consequently, current "international refugee law" seems insufficient to counter the new migrations, including those related to environmental disasters.

\section{The Impact of Climate Change on Human Security}

In 2007, the UN Secretary-General, Ban Ki-moon, attributed the violence in Darfur to a mixture of demographic pressures, water scarcity, and climate change, while the Christian Aid report (2007) warned that the Darfur model could be repeated around the world. In April of the same year, the UK government brought the climate change issue to the UN Security Council for the first time, citing the Darfur issue (Harvey, 2007). In the US, the Center for Defense Studies (CAN) released a report entitled "National Security and the Threat of Climate Change" (CAN Corporation), which acknowledged that "global warming" could be a factor in the widespread political instability in poor areas and a reason for large refugee movements to the US and Europe. Finally, toward the end of that year, the Norwegian Nobel Committee warned that climate-induced migration and scarcity of resources could cause violent conflict and war within and between countries.

In a report published in February 2019, the World Watch research center indicated that climate change in Africa will increase both poverty and internal instability. This in turn fuels terrorism and crime, and may push youth toward joining armed organizations, as in the Sahel, Sahara, and West Africa regions where environmental and social factors play a role in the emergence of violence within society, whether from a tribal or ethnic aspect or through the emergence of extremist organizations. The Global Climate Risk Index of 2019 shows that developing countries are the most affected by climate change problems (Eckstein, Hutfils, \& Winges, 2018).

According to the Fragile States Index issued by the Peace Fund, the Horn of Africa is also suffering from the aggravation of climate problems, particularly Somalia, Kenya, and Eritrea. These countries score high on indicators of vi- 
olence, one of the causes of which is identified as "climate change," particularly conflicts caused by droughts (Terdiman, 2018). Since 2011, Somalia has suffered droughts linked to climate change and in that period, researcher Marcus King at George Washington University in the US, noticed that the Shabab Movement (a youth movement) had changed its field action plan to isolate liberated cities from their basic hold on water resources (Werrel \& Femia, 2018).

In 2018, at the World Economic Forum, it was noted that the drought in Lake Chad had boosted extremist groups' efforts to spread, particularly "Boko Haram" and "Al Qaeda" in the Sahel region. This was largely because, in 2018, Mali witnessed an escalation in violence between farmers and herders and the number of people in need of food reached 5.2 million due to the escalation of violence and drought (World Economic Forum, 2019).

In Cameroon, one of the main reasons why young people are joining Boko Haram is the climate changes that have affected the agricultural environment, increasing desertification. As a result, many young people are joining armed groups in the Lake Chad region, where drought has led to the conviction that joining these groups is the best way to "stay alive and survive" (Gerretsen, 2019).

Confirmation of this hypothesis comes from the report issued by the German Foreign Ministry in 2017, which found that one reason for the spread of Islamic State (ISIS) in Syria was that water scarcity in some Syrian cities helped ISIS to recruit youth and spread its ideas through its work to provide water for the people (Lukas \& Rüttinger, 2016).

\section{Climate Change and Internal Displacement in Africa}

At the end of 2018, the number of internally displaced persons in Africa as a result of conflict and violence reached 16.8 million, representing 40 percent of the global total. This is the highest number ever recorded on the continent. Disasters alone, particularly linked to hydro-meteorological hazards such as floods, storms, and droughts, caused 2.6 million new displacements during that year. In 2019 , conflicts and disaster events suggest that the number of displacements is likely to continue to rise, indicating that this phenomenon should not be underestimated (IDMC, 2019).

Strikingly, most environmental refugees come from the Sahel and African desert region, which includes approximately 17 African countries, from Senegal in West Africa to northern Eritrea in East Africa. Most residents of this region suffer from threats associated with climate change. The political instability caused by civil wars, military coups, and lack of respect for human rights helps push the people of rural and nomadic areas to cross national borders in search of salvation. However, some $70 \%$ of African migrants had to leave their home countries due to poverty and unemployment. As almost $64 \%$ of African people, and approximately $90 \%$ of Ethiopians in particular, depend on agriculture for their livelihoods, the environmental variable has become critical in terms of the new trends of the refugee phenomenon in Africa (IDMC, 2019). Thus, climate 
migration has become an increasing problem. For example, UN officials estimate that approximately $10 \%$ of the nearly 300,000 refugees in Dadaab refugee camp in northern Kenya are climate-related.

Africa, particularly sub-Saharan Africa, is a rapidly developing region with great cultural, climatic, and environmental diversity (NASAC, 2015). By 2050, its population is expected to reach two billion, rising to nearly four billion by 2100 (DeSA, UN 2013). The agricultural sector employs approximately $65 \%$ of the workforce in Africa. While production of this sector has increased since 2000 due to the expansion of the agricultural area (World Bank, 2013), limited water and food mean that there is still a higher requirement for increased agricultural production (Mueller, Gerber, Johnston, Ray, Ramankutty, \& Foley, 2012). Agricultural production in sub-Saharan Africa is particularly vulnerable to climate change, as rain-fed agriculture accounts for almost $96 \%$ of total crop production (World Bank, 2015).

The Horn of Africa region has already faced alarming environmental degradation, generating massive economic and social famines and producing widespread conflicts over resources. Over the last half of the 20th century, the region's temperatures have tended to increase, while rainfall rates have tended to decrease. Historic temperature increases have had major negative impacts on agricultural added-value in African countries. Furthermore, a $1^{\circ} \mathrm{C}$ increase in temperature is associated with a $2.66 \%$ decrease in the growth of agricultural production, leading to estimates of a decrease in economic growth by 1.3 percentage points for each degree of warming (Dell, Jones, \& Jones, 2012) as well as a decrease in export growth by 2.0 to 5.6 percentage points (Jones \& Olken, 2010).

In the same period, large fertile and semi-fertile sectors of the region experienced rapid degradation in the form of deforestation, loss of plants, and biological diversity, and increased soil erosion, stiffness, and desertification. Although the causes of the increasing deterioration may not yet be fully known, they are linked to global climate change and various local human activities. Likewise, while it is difficult to determine the actual effects and potential impact of such degradation, it undoubtedly represents an increasing threat to human security in this region.

The environmental crisis in Africa is due to two main factors: The first is global climate changes that have affected several regions around the world; the second is regional human activities leading to changes in land use. Regarding the first factor, these changes are reflected in three phenomena:

\section{1) Changes in Temperature}

There are two scenarios for heat emissions. The first is the low-emission scenario RCP 2.6 (which represents the world adding $2^{\circ} \mathrm{C}$ ); in this scenario, by 2050 , summer temperatures in Africa will rise by approximately $1.5^{\circ} \mathrm{C}$ above the baseline of 1951-1980, and will remain at this level until the end of the century. In the RCP 8.5 (where the emission scenario is a global increase of $4^{\circ} \mathrm{C}$ ), warming continues until the end of the century, with monthly summer temperatures in sub-Saharan Africa reaching an additional $5^{\circ} \mathrm{C}$ above the baseline of 
1951-1980 by 2100 .

This warming is to be distributed fairly in a unified way geographically, although the interior regions in the subtropical regions will be even warmer, whereas in sub-tropical southern Africa, there will be a particularly large difference in warming between RCP2.6 and RCP8.5, likely due to positive reactions with rainfall (Serdeczny, Adams, Baarsch, Coumou, Robinson, Hare, \& Reinhardt, 2017).

\section{2) Maximum Temperatures}

The maximum temperatures are known as the temperatures of 3 and 5 sigma (standard deviations, degree of dispersion) (Schellnhuber, Hare, Serdeczny, Schaeffer, Adams, Baarsch, \& Piontek, 2013) and they are higher than the historical base for temperatures. Temperatures are maximized according to the two emissions scenarios (high and low):

- In the high emission scenario, by 2100 , more than $75 \%$ of the summer months will be hotter than 5 sigma, which is much higher than the global average, and during the period 2071-2099, more than half of the summer months in sub-Saharan Africa (approximately 60\%) will be hotter than 5 sigma, with a significant increase in West Africa (approx. 90\%).

- In the low emission scenario, a significant increase in extreme temperatures is expected in the near term by $30 \%$ of the land area of South Africa, and approximately $5 \%$ of West Africa (Jones \& Olken, 2010).

\section{3) Drought}

The long-term balance between demand and supply is a fundamental determinant of ecosystems and agricultural systems that can thrive in a particular region. This is referred to as the Arable Index (AI), which identifies "arable" areas, that is, regions with structural deficits in rainfall. The Arable Index (AI) is defined as the annual total precipitation (of rainfall) divided by potential evaporation. Generally, the annual average of possible monthly evaporation increases under global warming, as it is primarily driven by heat. This is already being observed across sub-Saharan Africa with a strong typical agreement, with the exception of regions that are expected to experience a significant increase in rainfall.

In East Africa and the Sahel region, there is a slight decrease in potential evaporation, and, by contrast, a more ambiguous sign is emerging in areas that are expected to receive less rain (particularly South Africa) (Zomer, Trabucco, Bossio, \& Verchot, 2008). For example, a multi-year drought-stricken Ethiopia reflected the displacement of 425,000 people. In a new report focusing on the Somali region in Ethiopia, the Internal Displacement Monitoring Center (IDMC) confirms that "the conflict over resources and ethnic violence led to more displacement in Ethiopia than any other country in the world in 2018."

The Sahel, Horn of Africa, and Southern Africa are the regions most affected by drought in the continent, with rainfall in the Sahel region falling by more than $20 \%$ since the early 1970 s in "one of the most dramatic long-term climate changes anywhere in the world" (Brooks, 2018). Niger experienced severe 
droughts in 1973 and 1984 and scarce and unreliable rains continue to affect rural communities. A significant feed shortage in 2018 also led to thousands of students dropping out of school, as children of pastoralists and agricultural herders had to follow their parents in search of pastures (OCHA, 2018).

Climate change leads to displacement of individuals in many ways. The most obvious and tragic is due to the increase in the number and seriousness of weather-related disasters, which destroy homes and force individuals to search for shelter elsewhere. Slow-starting phenomena, such as desertification and rising sea levels, are gradually destroying livelihoods and forcing societies to abandon their traditional homelands for more suitable environments. This is currently occurring in the African Sahel regions and the semi-arid climate zone belt, which extends around the continent just below its northern desert. Environments degraded as a result of climate change can lead to more resource-based conflicts, which may, in turn, lead to the displacement of individuals.

The second factor associated with regional human activities that lead to changes in land use (Solomon, Birhane, Gordon, Haile, Taheri, Azadi, et al., 2018) was demonstrated by the rapid population growth over the last half of the 20th century in the African continent, where the region's population has more than doubled since the early 1960s. As a result, there have been notable changes in the ratio, extent, and intensity of land use, as a result of bulldozing more agricultural land and cutting more trees for construction and logging. Despite the rapid urban growth, this region still houses the largest groups of pastoralists in the world. With the increasing population and livestock population, and with the increase in the number and length of droughts and overgrazing, lack of good pastures has become serious problems in several parts of the region.

Another human factor that has aggravated environmental degradation is the state's seizure of lands belonging to different population sects to give to foreign investors. This eliminates citizens' inherent land rights, as governments have been granting land concessions and waivers to extractive industries for decades. Moreover, in recent years, these governments have also been giving land to foreign investors for large-scale commercial agriculture.

Although the extractive industries sector is relatively small in the Horn of Africa, the governments of the region have already granted large land concessions to foreign investors. Furthermore, although exact numbers remain unknown, oral evidence indicates that these concessions are so large that they affect the environment. Countries of the region, except Djibouti, which has limited mineral resources, have attempted to expand their extractive industries. Although there are no accurate estimates, large areas have undoubtedly been taken away from their original owners.

The expansion of extractive industries and commercial agriculture contributes to the deterioration of the environment in both direct and indirect ways. Both mining and commercial agriculture require land leveling, which contributes to deforestation, declining vegetation, soil erosion, stiffness, and desertification. They also contribute to environmental degradation by emitting various pollu- 
tants into the air, water and soil. For example, oil spills in Sudan have become a major source of water and soil pollution, causing serious environmental impacts, most notably:

Famines and food insecurity (Solomon, Birhane, Gordon, Haile, Taheri, Azadi, et al. 2018): With the erratic rains and recurrence of prolonged droughts, the region has suffered from periodic famines. The two Ethiopian famines in 1974 and 1984 were the most severe in the region in recent years. Apart from these widespread famines, pastoral and peasant groups in the region regularly face famines, malnutrition, and livestock famines. Furthermore, local famines are occurring more regularly in all countries of the region, which is witnessing an increasing number of climate refugees, as the persistent droughts compel farmers and nomads to migrate to cities or refugee camps to avoid starvation.

The water and energy crisis (MacDonald, Calow, MacDonald, Darling, \& Dochartaigh 2009): With the increasing droughts, almost every country in the region faces increasing water and energy shortages, which have caused serious economic turmoil, not only for the peasants and herders, but for other sectors of the economy. In July 2009, Kenyan newspapers reported that Lake Kamnarok in the Great Rift Valley of Kenya had dried up, resulting in the loss of wildlife. Water has also dried up in Lake Nakuru National Park, while Lake Naivasha has shrunk considerably.

Likewise, the water levels in the three water stores in Nairobi-Ndakaini, Sasomoa, and Mombasa - were seriously low, causing a water crisis. Additionally, the power plant on the Tana River in Kenya was forced to close due to a drop in the water levels behind the river dam, which caused an energy deficit; some factories in Nakuru, including the Flamingo and Coil Products of Kenya and Cape, were also closed due to the water crisis.

During the same period, Ethiopia witnessed the drying of Lake Haramaya in the Oromia region. The state was forced to rationalize water and electricity due to the low water levels in the dams, and gas stations in various parts of the state have either become idle or are operated through a shift system.

Soil erosion, declining production, and extreme poverty (Schlenker \& Lobell, 2010): The International Climate Change Committee (IPCC) 2019 indicates significant risks to the agricultural sector, particularly to the yields of major cereal crops in the African region. "Worst case" predictions indicate losses of 27 to 32 percent for corn, sorghum, and peanuts due to temperature increases of approximately $2^{\circ} \mathrm{C}$ above pre-industrial levels by mid-century.

Sectarian conflicts (Solomon, Birhane, Gordon, Haile, Taheri, Azadi, \& Scheffran, 2018): Although scholars disagree about the relationship between environmental degradation and sectarian conflict, in the Horn of Africa, several cases of conflict have deteriorated the environmental degradation, if not been their primary cause. For example, worsening environmental degradation undoubtedly undermines the institutional mechanisms governing access to land and water, and it has become very common to witness pastoral raids across customary and sectarian boundaries in search of water and pastures. 
These conditions have led to various conflicts in the region. It is clear that the terrible conflict in Darfur is linked to the disturbances caused by environmental degradation, but mostly indirectly, the scarcity of water and land, generated by recurring droughts, has undermined the traditional norms governing access to these vital resources, thereby creating conditions for conflict.

Change in the Savannah forests ecosystem (Gonzalez, Tucker, \& Sy, 2012): The Savannah forests are considered part of the sub-Saharan African ecosystem and their vegetation is highly affected by climate change. The observed changes in tree cover in South Africa are due to an increased concentration of carbon dioxide or nitrogen deposition in the atmosphere. On the West Coast, a 20\% decrease in tree density and a significant decrease in species richness across the coast were observed in the second half of the $20^{\text {th }}$ century, due to changes in temperature and rainfall fluctuations.

\section{African Efforts to Combat Climate Change}

The increase in internal displacement in Africa over the past decade shows that the measures required to bring peace, improve security, reduce disaster risks, adapt to climate change, or enhance the sustainable development efforts are insufficient. New policy developments are vital to provide effective solutions that address displacement and reduce future risks.

African countries are well positioned to take the lead in this sense, as the African Union declared 2019 the Year of Refugees, Returnees, and Internally Displaced Persons (IDPs) to celebrate the tenth anniversary of the Kampala Convention, a unique and legally-binding regional mechanism on internal displacement that serves as a solid foundation for governments to develop their policies and procedures (African Union, 2009).

Some countries have taken steps to introduce national frameworks handling this phenomenon, even before the agreement enters into force. Yet, there is much to be done in terms of implementation and follow-up, as well as linking measures to address displacement with other social and economic developmental policies.

Three main stages of the development of African policies toward refugees can be distinguished:

Stage one: This is the stage of "open door policy" from the early 1960s to late 1980 s, characterized by welcoming refugees within the framework of the agreement that the Organization of African Unity (OAU) adopted in 1969 (Nyanduga, 2004).

Stage two: From 1990 to 2001, the security risks and economic burdens of the refugee phenomenon increased, leading to an end to the "open door policy." This transformation is one of the most prominent factors contributing to the increasing gravity of the refugee phenomenon in Africa, due to increased trans-national and cross-border refugees between countries of origin and refugee-receiving countries in the African context. The negative effects associated with refugee camps in host countries, such as crime, environmental damage, and 
depletion of limited resources, have prompted many African countries to refuse refugees from other countries (Nyanduga, 2004).

Stage three: This stage includes the years after the establishment of the "African Union," the turning point being the African Union's invitation to its member states to consider "forced displacement" as a "violation of human rights." The 2003 Kigali Declaration on Human Rights enshrined and confirmed this new approach, and the Kampala Convention was adopted in 2009, which sets standards to protect the rights of people displaced by conflict, violence, disasters, and human rights violations. The Convention provides a common understanding of the issue, and extends recommendations to support countries to take advantage of lessons learned at the national level. It is also calling for responses adapted to specific displacement situations, and encourages greater coordination by clearly defining roles and responsibilities between national and international stakeholders (IDMC, 2016).

These African efforts have occurred on both the international and regional levels of agreements on climate change.

\subsection{The International Level (Parties Agreements)}

Parties agreements are agreements on global issues that are not specifically related to a given region, but rather include all countries worldwide. They are concerned with the future treatment of the issue, including the framework issues of climate change. They include the UN Framework Convention on Climate Change of 1992 and the Kyoto Convention of 1997, which entered into force in 2005 , as a response from the international community to the challenges posed by climate change. The Kyoto Convention has been ratified by 194 countries and includes several obligations (Diniz, 2007).

A-The joint implementation mechanism and exchange of emission release rights:

According to this mechanism, countries of the European Union, former Soviet Union, Eastern Europe, America, and Japan may exchange with one another the allowed emissions, by either purchasing the emissions' licenses if the emission reduction measures have not been taken, or by financing projects that enable emissions' reductions in another country.

B-Clean Development Mechanism:

This mechanism allows developing countries to obtain financing from developed countries to finance clean projects and transfer appropriate technology. Despite these efforts, the Kyoto Protocol has failed to reduce emissions, which have in fact increased by $25 \%$ since the negotiation of the protocol and developing countries believe that the Kyoto Protocol has only provided limited support for them (World Bank, 2010). Within the scope of the protocol, African countries are not concerned with reducing greenhouse gas emissions, but they are obliged to prepare national reports on climate change and the overall institutional and legal measures taken. The framework treaty also impacted African countries; although these countries do not contribute to high greenhouse gas emis- 
sions, the effects of emissions may affect coastal areas and dry-lands of the continent. In fact, 47 African countries have ratified the treaty, as it addressed the "type of threat" that climate change would cause to each region in Africa, focused on researching crop varieties that would allow South African countries to adapt to climate change, and supported the Southern African Development Authority's drought monitoring center.

In the context of natural disaster management, the UN called for a conference on January 22, 2005 to discuss ways to address natural disasters under the Hyogo Framework for Action 2005-2015, which aims to build the capacity of nations to cope with disasters. This plan urged the necessity of exchanges between countries, particularly satellite data forecasts about endangered and threatened areas.

The Hyogo Framework for Action considered the disaster in Africa to be a major obstacle to the continent's efforts to achieve sustainable development, particularly given the region's insufficient capacities to predict, monitor, respond to, and mitigate disasters. Therefore, it was recognized that efforts must be made to provide financial and technical assistance to enhance African countries' capabilities in acquiring monitoring, early warning, assessment, prevention, and preparedness systems (Olowu, 2010).

Bali Conference came to chart the course of action for the post-2012 stage through two main tracks:

Track one: the path of the ad-hoc working group on additional obligations for Parties included in "Appendix A" under the Kyoto Protocol.

Track two: the path of the ad-hoc working group on long-term cooperative action.

The overall objectives of the project revolve around two main components (UNFCCC, 2007):

A. Increased national capacity to coordinate ministerial views and participate in the process of the "United Nations Framework Convention on Climate Change" (UNFCCC) and negotiate positions within the deadline of the "Bali Action Plan."

B. Evaluating investments and financial flows to address climate change in three main sectors (power generation, energy-intensive industries, and domestic sectors, including housing and transportation sectors).

Difficulties that the African countries faced at the Bali conference:

Bali Map 2007, or the "Bali Action Plan," focused on four thematic elements: adaptation, mitigation, technology transfer, and financing.

1) Adaptation is a sustainable and continuous response process to changing and renewable environmental conditions. The secretariat of the UNFCCC estimated that by 2030 , developing countries would need some $\$ 67,228$ billion to cover the costs of adapting to climate change, equivalent to 0.2 to $0.8 \%$ of global investment flows, or only $0.06 \%$ to $0.21 \%$ of the expected global GDP for the year 2030. According to the World Bank, the additional costs of adapting to the expected climate change in developing countries will reach from 10 to 40 billion dollars per year. These high sums far exceed the amounts currently available 
through the UNFCCC funds and other existing resources. Developing countries have expressed the need for developed countries to fulfill their financing responsibilities in terms of capacity building for developing countries, yet progress on this issue remains slow (Burleson, 2008).

2) Reducing the Impact means lowering greenhouse gas emissions, a foundational issue of climate change negotiations since their inception. The focus here was on "mitigation" measures that developing countries can take, including their responsibility in conjunction with developed countries to take "measurable, reporting, and verifying" mitigation measures.

These measures comprise commitments to incrementally reduce emissions (i.e., from bottom up) to achieve reductions to the emission baseline. These measures must be technology-supported and funded; and such technology and funding elements themselves constitute an obstacle to the policy makers of developing countries.

3) Technology Transfer: Green technology is not being developed at the necessary rate due to a number of technological and financial barriers for developing countries, including: finding a way to accelerate the reduction of carbon emissions from energy worldwide, and determining the necessary political approach for accelerating, developing, and deploying the technology (i.e., having policies on climate issues alone or additional political and technological tools), the possibility of finding ways to effectively achieve a significant change in investments toward sustainable technology, and dealing with the debate regarding the role of intellectual property rights in developing green technology.

4) Financing: Developing countries need important financial assistance to tackle mitigation, adaptation, and technology. Therefore, these countries will need to assess the current arrangements for financial assistance provided under the Kyoto Protocol, as well as the options in the current negotiations on increasing investment and financial flows to counteract climate change. This represents a challenge for developing countries in light of the withdrawal of several countries from the protocol, such as Russia, Japan, New Zealand, Canada, and the US.

\subsection{The Regional Level}

The 2009 Kampala Convention states that governments bear the primary responsibility for protecting and assisting internally displaced persons and that they should integrate the provisions of the Convention into their national legislation and policies. Forty out of 55 African Union member states have signed the Kampala agreement, and 29 countries have ratified it; however, only one country, Niger, has integrated it into its national legislation (Union, 2019).

The Kampala agreement was an important catalyst for increasing government responsibility for internal displacement. Since the adoption of the agreement, Burundi, Ethiopia, the Democratic Republic of the Congo, Niger, Mali, Somalia, South Sudan, Sudan, and Zambia have developed relevant laws or policies, some of which are more comprehensive than others in terms of the causes and stages 
of displacement that they cover. Moreover, some apply at the national level, while others are on specific areas.

In 2018, the African Union created a model law to support African countries in developing their national laws in line with the agreement (Union, 2018). A group of countries have adopted policies related to the return and reintegration of internally displaced persons, but such policies do not include specific measures or clear solutions to prevent new displacement. Several also have specific provisions to limit displacement. Overall, displacement problems may have taken their course in becoming integrated into African national policies.

To activate more accurate and effective policies, initiatives have been taken to incorporate measures aimed at reducing poverty or improving access to housing, health, education, and other basic services. These methods have a number of benefits: they are more adaptable to local realities and capabilities; they can target challenges beyond those that the displacement represents; and they can help attract direct investments and raise more targeted funds. "New Partnership for Africa's Development" (NEPAD), was one of these initiative, it is an economic development program of the African Union. NEPAD is the first approach to comprehensive development that African governments follow with the full support of the international community. NEPAD provides a vision for the type of society and economy that governments wish to build; it is not only a framework, philosophy, or vision for development, but rather a program for development, as it represents concrete projects aimed at meeting Africa's development needs and overcoming the challenges it faces in this field. The NEPAD initiative also focused on sustainable development and climate issues (Biswas, 2004). Likewise, in "Vision 2063," Africa was concerned with climate issues as a critical issue, by paying attention to sustainable development issues in general.

\section{Conclusion}

With the increase in greenhouse gas emissions and environmental problems, it is difficult for Africa to recover from climate change problems for several reasons:

1) Low adaptive capacity, as described by Oliver Ruppel (2013) in his article on how climate change threatens human security and causes conflict. According to the Intergovernmental Panel on Climate Change, the ability to adapt is "the ability of systems, institutions, people and other organisms to adapt to potential harm," and this is what the continent lacks.

2) Lack of agreement on the correct language to describe refugees without taking the necessary legal measures, as there is no legal recognition of a climate refugee or environmental refugee. Biermann and Boas (2012) assert that the term "refugee" has strong moral connotations to protect society in most cultures and religions; moreover, this term will give climate refugee protection the legitimacy and urgency it deserves. Therefore, a greater global effort must be made to develop clear terms that refer to "climate refugees." Once these guidelines are established, new international policies must be established to accommodate them. 
3) The loss of environmental justice in the United Nations' agreements, as successive party conferences reflected the reality of contradictory visions between the countries of the south and countries of the north, with the former believing that they should not have to bear the bill for the latter, while the latter refuse to bear the material cost alone. This situation has led to difficulties implementing the decisions issued by these conferences, particularly after the US announced its withdrawal from commitment to the Paris COP21 conference, considered one of the most important climate change conferences.

Consequently, it has become a must for the whole world to follow the notions that both Bierman and Boas (2012) suggested, i.e. "the principle of international burden-sharing" or "the ideal of funding assistance for climate refugees on a global scale," while ensuring that this principle should include "common but differentiated responsibilities" for the different countries of the world. Nevertheless, this should be associated with realizing that developed countries should bear the moral responsibility for their actions and pay a larger share in assistance than less wealthy countries. Another basic measure is to adopt a legal climate refugee term that extends the scope of the refugee status to include and integrate "climate change refugees".

\section{Conflicts of Interest}

The author declares no conflicts of interest regarding the publication of this paper.

\section{References}

Aid, C. (2007). Human Tide: The Real Migration Crisis. http://www.christian-aid.org.uk

Bates, D. C. (2002). Environmental Refugees? Classifying Human Migrations Caused by Environmental Change. Population and Environment, 23, 465-477. https://doi.org/10.1023/A:1015186001919

Biermann, F., \& Boas, I. (2012). Climate Change and Human Migration: Towards a Global Governance System to Protect Climate Refugees. In Climate Change, Human Security and Violent Conflict (pp. 291-300). Berlin: Springer. https://doi.org/10.1007/978-3-642-28626-1_15

Biswas, A. (2004). NEPAD: Forum for Growth and Unity. Economic and Political Week$1 y, 39,793-796$.

Brooks, N. (2018). Climate Change, Drought and Pastoralism in the Sahel: Discussion Note for the World Initiative on Sustainable Pastoralism.

https://www.iucn.org/sites/dev/files/import/downloads/e conference discussion note for the world initiative on sustainable pastoralism .pdf

Burleson, E. (2008). The Bali Climate Change Conference. American Society of International Law Insights, 12. https://ssrn.com/abstract $=1107667$

CAN Corporation (2007). National Security and Threat of Climate Change Report. https://www.cna.org/cna files/pdf/national\%20security $\% 20$ and $\% 20$ the $\% 20$ threat $\% 20$ of \%20climate\%20change.pdf

Dell, M., Jones, B. F., \& Olken, B. A. (2012). Temperature Shocks and Economic Growth: Evidence from the Last Half Century. American Economic Journal: Macroeconomics, 


\section{4, 66-95. https://doi.org/10.1257/mac.4.3.66}

DeSA, U. N. (2013). World Population Prospects: The 2012 Revision (p. 18). New York: Population Division of the Department of Economic and Social Affairs of the United Nations Secretariat.

Deudney, D. (1990). The Case against Linking Environmental Degradation and National Security. Millennium, 19, 461-476. https://doi.org/10.1177/03058298900190031001

Diniz, E. M. (2007). Lessons from the Kyoto Protocol. Ambiente \& Sociedade, 10, 27-38. https://doi.org/10.1590/S1414-753X2007000100003

Eckersley, R. (2007). Ecological Intervention: Prospects and Limits. Ethics \& International Affairs, 21, 293-316. https://doi.org/10.1111/j.1747-7093.2007.00101.x

Eckstein, D., Hutfils, M. L., \& Winges, M. (2018). Global Climate Risk Index 2019: Who Suffers Most from Extreme Weather Events? Weather-Related Loss Events in 2017 and 1998 to 2017. Germanwatch Nord-Süd Initiative eV.

El-Hinnawi, E. (1985). Environmental Refugees. Unep.

Gerretsen, I. (2019). How Climate Change Is Fueling Extremism. CNN News, March, 10.

Gonzalez, P., Tucker, C. J., \& Sy, H. (2012). Tree Density and Species Decline in the African Sahel Attributable to Climate. Journal of Arid Environments, 78, 55-64. https://doi.org/10.1016/j.jaridenv.2011.11.001

Harvey, F. (2007). UN Climate Panel Detailed Potential for Global Conflict. Financial Times, 13.

Hugo, G. (1996). Environmental Concerns and International Migration. International Migration Review, 30, 105-131. https://doi.org/10.1177/019791839603000110

Internal Displacement Monitoring Centre (IDMC) (2016). From Kampala to Istanbul, Advancing Global Accountability for IDPs through Law and Policy Making. https://www.internal-displacement.org/publications/from-kampala-to-istanbul-advanc ing-global-accountability-for-idps-through-law-and

Internal Displacement Monitoring Centre (IDMC) (2019). Africa Report of Internal Displacement. https://www.internal-displacement.org/africa-report

Intergovernmental Panel on Climate Change (IPCC) (2019). Climate Change and Land: Summary for Policymakers. An IPCC Special Report on Climate Change, Desertification, Land Degradation, Sustainable Land Management, Food Security, and Greenhouse Gas Fluxes in Terrestrial Ecosystems.

Jones, B. F., \& Olken, B. A. (2010). Climate Shocks and Exports. American Economic Review, 100, 454-459. https://doi.org/10.1257/aer.100.2.454

Lonergan, S. (1998). The Role of Environmental Degradation in Population Displacement. Environmental Change and Security Project Report, 4, 5-15.

Lukas, K., \& Rüttinger, L. (2016). Insurgency, Terrorism and Organised Crime in a Warming Climate: Analysing the Links between Climate Change and Non-State Armed Groups. Adelphi.

MacDonald, A. M., Calow, R. C., MacDonald, D. M., Darling, W. G., \& Dochartaigh, B. E. (2009). What Impact Will Climate Change Have on Rural Groundwater Supplies in Africa? Hydrological Sciences Journal, 54, 690-703.

https://doi.org/10.1623/hysj.54.4.690

Mueller, N. D., Gerber, J. S., Johnston, M., Ray, D. K., Ramankutty, N., \& Foley, J. A. (2012). Closing Yield Gaps through Nutrient and Water Management. Nature, 490, 254-257. https://doi.org/10.1038/nature11420

Myers, N. (1993). Environmental Refugees in a Globally Warmed World. Bioscience, 43, 
752-761. https://doi.org/10.2307/1312319

NASAC (2015). Climate Change Adaptation and Resilience in Africa: Recommendations to Policymakers, Network of African Science Academies.

https://nasaconline.org/index.php/2016/09/12/climate-change-adaptation-and-resilien ce-in-africa-recommendations-to-policymakers-2

Nyanduga, B. T. M. (2004). Refugee Protection under the 1969 OAU Convention Governing the Specific Aspects of Refugee Problems in Africa. German YB Int'l L., 47, 85.

OCHA (2018). Nigeria: Humanitarian Response Plan. https://reliefweb.int/report/nigeria/nigeria-humanitarian-response-plan-january-dece $\underline{\text { mber- } 2018}$

Olowu, D. (2010). The Hyogo Framework for Action and Its Implications for Disaster Management and Reduction in Africa. JAMBA: Journal of Disaster Risk Studies, 3, 303-320. https://doi.org/10.4102/jamba.v3i1.22

Paterson, M. (2000). Understanding Global Environmental Politics: Domination, Accumulation, Resistance. Berlin: Springer. https://doi.org/10.1057/9780230536777

Renaud, F. G., Dun, O., Warner, K., \& Bogardi, J. (2011). A Decision Framework for Environmentally Induced Migration. International Migration, 49, e5-e29. https://doi.org/10.1111/j.1468-2435.2010.00678.x

Ruppel, O. C., \& Van Wyk, S. (2013). Climate-Change-Induced Movement of Persons in Africa: Human Rights Responses to Aspects of Human Security. In Climate Change: International Law and Global Governance (pp. 799-826). Baden-Baden: Nomos VerlagsgesellschaftmbH \& Co. KG. https://doi.org/10.5771/9783845242774 799

Schellnhuber, H. J., Hare, B., Serdeczny, O., Schaeffer, M., Adams, S., Baarsch, F., \& Piontek, F. (2013). Turn Down the Heat: Climate Extremes, Regional Impacts, and the Case for Resilience.

Schlenker, W., \& Lobell, D. B. (2010). Robust Negative Impacts of Climate Change on African Agriculture. Environmental Research Letters, 5, 10-14. https://doi.org/10.1088/1748-9326/5/1/014010

Serdeczny, O., Adams, S., Baarsch, F., Coumou, D., Robinson, A., Hare, W., \& Reinhardt, J. (2017). Climate Change Impacts in Sub-Saharan Africa: From Physical Changes to Their Social Repercussions. Regional Environmental Change, 17, 1585-1600. https://doi.org/10.1007/s10113-015-0910-2

Solomon, N., Birhane, E., Gordon, C., Haile, M., Taheri, F., Azadi, H., \& Scheffran, J. (2018). Environmental Impacts and Causes of Conflict in the Horn of Africa: A Review. Earth-Science Reviews, 177, 284-290.

https://doi.org/10.1016/j.earscirev.2017.11.016

Terdiman, M. (2013). Climate Change and Conflict in Middle East and North Africa. https://rieas.gr/researchareas/global-issues/middle-east-studies/1935-climate-change-a nd-conflict-in-the-middle-east-and-north-africa

African Union (2009). Convention for the Protection and Assistance of Internally Displaced Persons in Africa (Kampala Convention). Adopted by the Special Summit of the Union Held in Kampala.

https://au.int/en/treaties/african-union-convention-protection-and-assistance-internall y-displaced-persons-africa

African Union (2018). Model Law for the Implementation of the African Union Convention for the Protection and/or Assistance to Internally Displaced Persons in Africa.

https://www.refworld.org/docid/5afc3a494.html

African Union (2019). List of Countries Which Have Signed, Ratified, Acceded to the 
Kampala Convention. https://au.int/sites/default/files/treaties/36846-sl

UNFCCC United Nations Climate Change Conference (2007). United Nations Framework Convention on Climate Change. http://unfccc.int/2860.php

Wackernagel, M., \& Rees, W. (1998). Our Ecological Footprint: Reducing Human Impact on the Earth (Vol. 9). Gabriola: New Society Publishers.

Werrel, C. E., \& Femia, F. (2018). Climate Change Raises Conflict Concerns. UNESCO Courier.

World Bank (2010). World Development Report 2010: Development and Climate Change.

http://documents.worldbank.org/curated/en/201001468159913657/World-developmen t-report-2010-development-and-climate-change

World Bank (2013). Fact Sheet: The World Bank and Agriculture in Africa, 2013. http://datatopics.worldbank.org/world-development-indicators/

World Bank (2015). Rainfed Agriculture.

http://water.worldbank.org/topics/agricultural-water-management/rainfed-agriculture

World Economic Forum (2019). The Sahel Is Engulfed by Violence. Climate Change, Food Insecurity and Extremists Are Largely to Blame.

https://www.weforum.org/agenda/2019/01/all-the-warning-signs-are-showing-in-the-s ahel-we-must-act-now

Zomer, R. J., Trabucco, A., Bossio, D. A., \& Verchot, L. V. (2008). Climate Change Mitigation: A Spatial Analysis of Global Land Suitability for Clean Development Mechanism Afforestation and Reforestation. Agriculture, Ecosystems \& Environment, 126, 67-80. https://doi.org/10.1016/j.agee.2008.01.014

Bates, D. C. (1996). Partners across Borders: August 1996 Delegation to El Salvador (Unpublished Internal Document). St. Cloud, MN: Partners across Borders. 